\title{
Constrictor Action of Substances in the Pulmonary Artery in Newborn with the Amnional Fluid Aspiration Syndrome (MAS)
}

\section{Hilmi Islami ${ }^{1 *}$, Ragip Shabani ${ }^{2}$, Naim Haliti ${ }^{3}$, Gani Dragusha ${ }^{4}$, Bajram Nuraj ${ }^{5}$ and Salih Ahmeti ${ }^{6}$}

${ }^{1}$ Department of Pharmacology, Faculty of Medicine, University of Prishtina, Kosova ${ }^{2}$ Department of Pathology, Faculty of Medicine, University of Prishtina, Kosova

${ }^{3}$ Department of Forensic Medicine, Faculty of Medicine. University of Prishtina, Kosova

${ }^{4}$ Department of Pharmacology, Faculty of Medicine, University of Prishtina, Kosova

${ }^{5}$ Department of Clinical Anatomy, Faculty of Medicine, University of Prishtina, Kosova

${ }^{6}$ Department of Infectology, Faculty of Medicine. University of Prishtina, Kosova

\section{Summary}

In this in vitro work, action of acetylcholine and histamine on pulmonary artery in live and dead newborn (250 up to $3000 \mathrm{~g}$ of body weight) which have died due to aspiration of amnional fluid was studied. Response of tracheal rings and pulmonary artery preparations on acetylcholine $10^{-4}, 10^{-3}, 10^{-2}, 10^{-1} \mathrm{~mol} / \mathrm{dm}^{3}$; and histamine: $10^{-4}, 10^{-3}, 10^{-2}, 10^{-1} \mathrm{~mol} /$ $\mathrm{dm}^{3}$ followed up. Response of tracheal smooth musculature was registered in a multi-channel registration (Watanabe HSE 6600) Statcham.

The action of acetylcholine in the pulmonary artery, in cases which has died due to aspiration of amnional fluid, has not experienced any significant change $(p>0.1)$, whilst histamine has caused constriction of the pulmonary artery in a significant manner $(p<0.01)$. Despite this, examination of tracheal rings in the controlling group with the meconial aspiration syndrome (MAS) and the group with lung atelectasis which have died from the distress respiratory syndrome (DRS), has caused significant response of tracheal smooth musculature $(p<0.01)$.

Aim of the work was to evaluate the effect of meconium at the newborn pulmonary artery. Results suggest that meconium does not increase in a significant manner the reactivity of the smooth musculature to acetylcholine but this reactivity is expressed in histamine. Relaxation can be explained with the fact that at the syndrome of meconial aspiration exist a high content of the magnesium in the meconium which can obstructs entry of the calcium in the cell interior by causing relaxant effect.

Keywords: Pulmonary artery; Trachea; Acetylcholine; Histamine

\section{Introduction}

Syndrome of the aspiration of the meconium fluid (MAS) is a complex severe disorder in newborn which manifest with respiratory distress, pulmonary hypertension and hypoxemia [1,2].

It is ascertained that meconium is present since $12^{\text {th }}$ gestation week of fetus. It is a product being released at the amniotic cavity, prior birth, as a consequence of the relaxation of the anal sphincter of the fetus. This presence of the meconium in the amniotic fluid can have, as a consequence, the aspiration of this fluid and manifesting of the severe forms of pneumonitis in early neonatal stages immediately following the delivery [3].

Amnional fluid contains stem cells, secretion of vernix caseosa, it contains also gastrointestinal system cells [4]. Composition of the meconium includes 4 different biliar acids (e.g. choline, chenodeoxycholic and lithocholic acid) and minerals such copper, zinc, manganese, calcium, iron, and phosphorus as most often ones $[5,6]$. Continuously, it contains plasmatic proteins (alpha-1 antitrypsin) $[7,8]$. Meconium is also composed of other different substances such interleukins IL-1ß, IL-6 and IL8, necrotizing tumoral factor (TNFalpha) [9] and phospholipases $\mathrm{A}_{2}\left(\mathrm{PLA}_{2}\right)$ [10] that might induce direct and indirect pulmonary inflammation by increasing the production of cytokines and by activating leukocytes or epithelial and endothelial cells of the lung. In vitro exposure of the meconium increases the release of IL-8, TNF-alpha [11], endothelium-1, trombocytes activating factor (PAF), leukotrienes, thromboxane $\mathrm{A}_{2}$, inducing of synthetase $\mathrm{NO}$ [12], NO [13], PLA ${ }_{2}$ and other substances that impact on reactibility of airways and inflammation.
It is supposed that in the early stages presence of the amniotic fluid can be associated with an increase of pulmonary resistance, dysfunction of surfactant, decrease of dynamic compliance of the lungs, hypoxemia with hypercapnia $[14,15]$.

All these changes progress in the representation of inflammatory changes which affect in changeability of the smooth musculature contractility and development of pulmonary hypertension. Respectively, these pathophysiologic processes are associated with changes in the tissue of airways smooth musculature and pulmonary vessels in a newborn $[16,17]$

Epithelial cells of the airways in the presence of the amnional fluid react with the release of thromboxane $\mathrm{A}_{2}$; respectively it is supposed that synthesis and/or activation of constrictor agonist in lung vascular vessels is stimulated [13].

Data from the researches in experimental animals are quite contradictory by referring that tracheal segments in rabbit exposed "in

*Corresponding author: Hilmi Islami, MD PhD, Institute of Clinical Pharmacology and Toxicology, Faculty of Medicine, Prishtina University, Tel: 0037745437 415; Fax: 0038138551 001; E-mail: islamihilmi@hotmail.com

Received December 10, 2011; Accepted December 18, 2011; Published December 19, 2011

Citation: Islami H, Shabani R, Haliti N, Dragusha G, Nuraj B, et al. (2011) Constrictor Action of Substances in the Pulmonary Artery in Newborn with the Amnional Fluid Aspiration Syndrome (MAS). Clin Exp Pharmacol 1:104. doi:10.4172/2161-1459.1000104

Copyright: (c) 2011 Islami $\mathrm{H}$, et al. This is an open-access article distributed under the terms of the Creative Commons Attribution License, which permits unrestricted use, distribution, and reproduction in any medium, provided the original author and source are credited. 
vitro" with meconium react with hyper-reactivity; whilst at tracheal segments in pre-contracted rat presence of meconium is associated with the relaxation of smooth musculature of these segments $[18,19]$.

Whereas in researches of human umbilical vessels exposed in the meconium are presented opposite data and thus in one research was declared that meconium does not contract the smooth musculature of umbilical vessels [20], whilst in another research was reported for direct vasoconstrictor effect of meconium in umbilical vessels [21].

Considering that structure of innervations, respectively contractility of airways smooth musculature and respiratory vascular vessels in human has some special features, we can conclude that the effect of amnional fluid in the smooth musculature of pulmonary vascular vessels respectively in the pulmonary artery and human tracheal segments is quite complex and is not yet entirely defined.

Therefore, aim of the work is to evaluate the effect of meconium in the pulmonary artery and tracheal segments at newborn through the action of vasoconstrictor substances such acetylcholine and histamine.

\section{Materials and Methods}

Research was conducted in cooperation with the Institute of Pharmacology, Pathologic Anatomy and Experimental Unit of the Faculty of Medicine in Prishtina, with the approval of the Ethic Committee by respecting principles of the Helsinki Declaration.

Classification was done based on histopathological analyses:

First controlling group (7) in recently dead children from: meconial fluid aspiration syndrome (MAS) is histopathologically characterized with changes as follows: presence of the amnional fluid in airways, with proteinic eosinophilic granular material and epithelial squama.

Second controlling group (8) in recently dead children from: pneumonia, bronchopneumonia, atelectasis and cerebral haemorrhage (RDS) is histopathologically characterized with changes as follows: within air spaces, up to the level of alveoli, many inflammatory infiltrates of the granulocyte, mastocyte and erythrocytary extravasate are noticed. In the bronchiole and peribronchially, proteinic eosinophilic material, cell detritus and many inflammatory infiltrates of the granulocyte, mastocyte, and monocyte types are noticed. Some lung parts (alveoli) are not opened.

Researches were performed in vitro in 7 experimental models in the segments of pulmonary artery in newborn that has died due to aspiration of fluid in different gestation weeks (with weight of 250 up to $3000 \mathrm{~g}$ ). Pulmonary artery was taken immediately after the autopsy by being placed in Krebs solution $(\mathrm{pH}=7.4)$.

During the experiment, water bath temperature was held in $37^{\circ} \mathrm{C}$, and solution in the water bath was aerosolized continuously with gas mixture $\left(95 \% \mathrm{O}_{2}\right.$ and $\left.5 \% \mathrm{O}_{2}\right)$, with continuous flow in the water bath solution. Tracheal rings from MAS and DRS death cases were prepared and serially connected in between themselves. Serial, composed of 6 rings, was placed in water bath for isolated organs ( $50 \mathrm{ml}$ volume), in order that lower part of the rings is connected for retainer, whilst upper part of the ring is connected with thread to transducer (Force transducer", Statham UC $\mathrm{UC}_{2}$ ). Response of TSM was registered in a multichannel registration (Watanabe HSE 6600).

30 minutes later, first tonus of tracheal rings was registered; afterwards preparation was exposed to different molar concentrations (acetylcholine: $10^{-4}, 10^{-3}, 10^{-2}, 10^{-1} \mathrm{~mol} / \mathrm{dm}^{3}$; histamine: $10^{-4}, 10^{-3}, 10^{-2}$ $\left.10^{-1} \mathrm{~mol} / \mathrm{dm}^{3}\right)$.

Doses have changed every 15 minutes, whilst effects of bronchiconstrictor agents, after the application, were monitored for 3 minutes. Afterwards, preparation got rinsed couple of times with Krebs solution, prior application of the other substance.

Results were processed with statistical computer software GraphPad InStat III with T-test for comparison of two working groups.

\section{Results}

Results of the in vitro research in isolated tracheal preparations in newborn shows that acetylcholine and histamine were applied in different molar concentrations (acetylcholine: $10^{-1}, 10^{-2}, 10^{-3}, 10^{-4} \mathrm{~mol} /$ $\mathrm{dm}^{3}$; histamine: $10^{-1}, 10^{-2}, 10^{-3}, 10^{-4} \mathrm{~mol} / \mathrm{dm}^{3}$ ) which act in a different manner depending from the applied dose to the pulmonary artery and tracheas in newborn with MAS and RDS syndrome.

In Figure 1, 2, 3 and 4, acetylcholine and histamine action in the pulmonary artery and isolated tracheas in the MAS and RDS syndrome are presented.

\section{Discussion}

Increase of the airways resistance is considered as an important component in MAS syndrome, despite the fact that some other mechanisms are involved also in causing of this syndrome. Composition

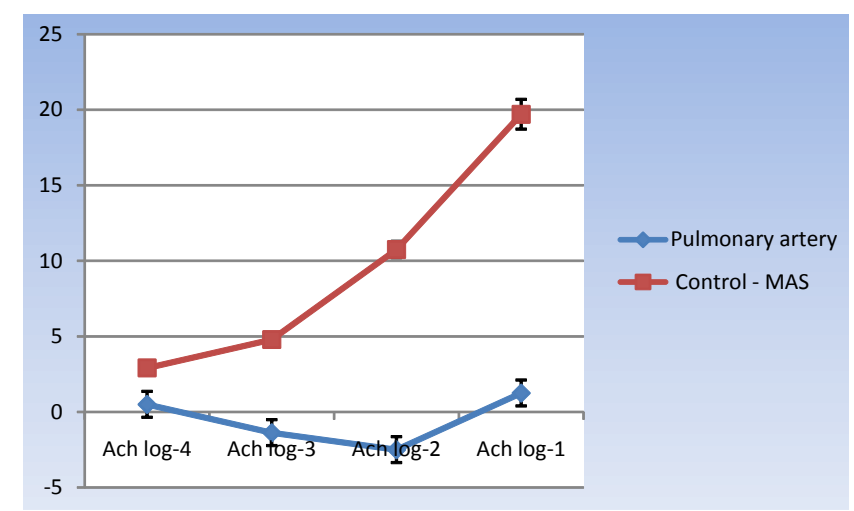

Figure 1: Action of acetylcholine and histamine in the pulmonary artery and isolated tracheas in the MAS and RDS syndrome.

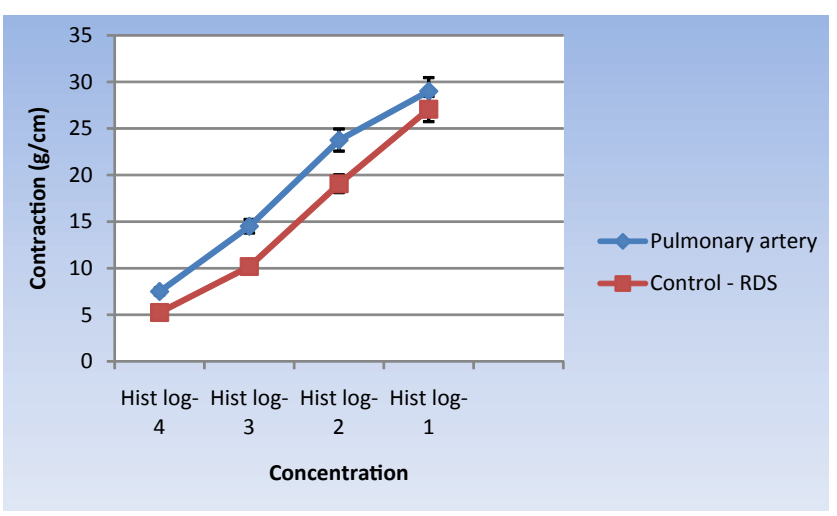

Figure 2: Action of acetylcholine and histamine in the pulmonary artery and isolated tracheas in the MAS and RDS syndrome. 


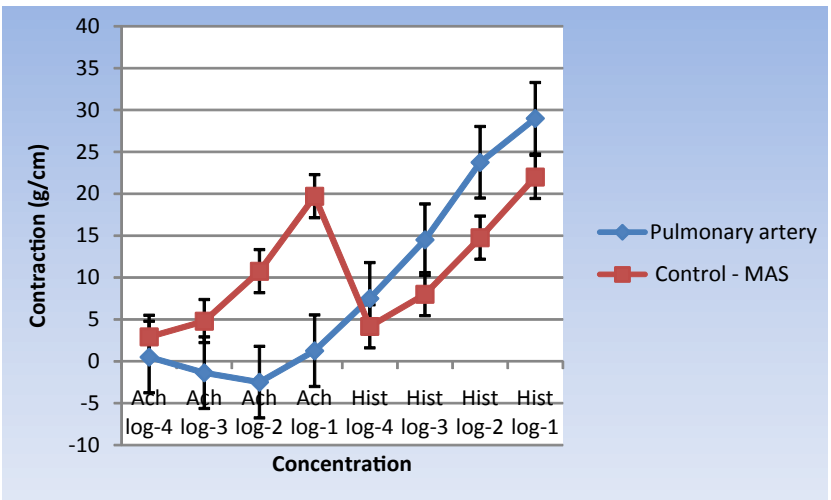

Figure 3: Action of acetylcholine and histamine in the pulmonary artery and isolated tracheas in the MAS and RDS syndrome.

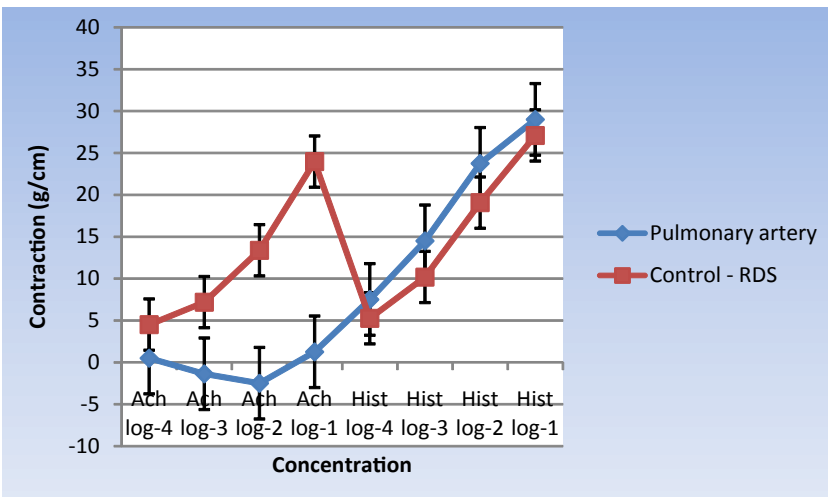

Figure 4: Action of acetylcholine and histamine in the pulmonary artery and isolated tracheas in the MAS and RDS syndrome.

of amniotic fluid is also quite heterogenic by mentioning here different tissue cells [22], plasmatic proteins ( $\alpha_{1}$-antitripsin and phospholipase $\mathrm{A}_{2,}[23,24]$, different biliar acids and different minerals such calcium salts, magnesium, zinc, and copper [25].

This composition of amniotic fluid, especially of minerals, may affect in terms of possibility that response of vascular vessels and tracheal segments in human can be complex.

Results of functional researches of isolated preparation of the pulmonary artery in dead newborn because of MAS syndrome in our research has showed that acetylcholine has not caused any significant vasoconstrictor effect ( $p>0.1$ ), whilst histamine has caused constriction of the pulmonary artery in a significant manner $(\mathrm{p}<0.01)$. Acetylcholine and histamine has caused significant constrictor reaction of the smooth musculature of the tracheal segments in the group of dead newborn from the MAS syndrome and the group of newborn that have died from the respiratory distress syndrome (RDS). Certainly, histamine stimulates the release of thromboxane A-2, and causes the constriction of TSM. Acetylcholine can cause the release of nitric oxide which has relaxant effect of the smooth musculature. Mechanism by which meconium causes direct relaxation of the smooth musculature of the pulmonary artery induced with acetylcholine remains unclear.

Syndrome of the meconial aspiration (MAS) is related with the pulmonary hypertension in newborn. Aspiration of meconial fluid in consecutive syndrome of pulmonary arterial hypertension in newborn remains currently unclear.

Exposure of epithelial cells of the airways in the meconium induces the release of thromboxane (A-2) [13], by suggesting that MAS syndrome in the pulmonary hypertension is related with the activation of agonists with constrictor action of the smooth vascular musculature.

High content of the magnesium in meconium plays an important role and hinders the entry of calcium in cells by causing relaxant effect of the smooth musculature in dogs [26]. Superoxide also increases the relaxation of musculature by entering into reaction with oxygen and by reducing bioavailability of the nitric oxide. Role of the oxygen in changing of the reaction of the smooth musculature of pulmonary artery is related with the syndrome of aspiration of the meconial fluid; this is also reported by other authors [27-31].

Results of the action of histamine in pulmonary artery in our research are not in compliance with the results of the author Tessler $\mathrm{R}$ with bp., which ascertains that human meconium has relaxing effect in the airways smooth musculature and vascular tissue of newborn and grown rats [32].

Even though, some author has ascertained the vasoconstrictor effect of the meconium in human umbilical vein [20,21].

Results of the action of histamine in the pulmonary artery in human material and results of acetylcholine and histamine action in tracheal segments in controlling groups in our research are in compliance with the abovementioned author.

Whilst, in researches "in vitro" in rats by author Collins [33], with bp. it is ascertained that meconium has no significant impact in increase of the airways smooth musculature tonus.

This conclusion of the abovementioned author also does not comply with results of our research where is ascertained that acetylcholine and histamine manifest significant response in 'in vitro' conditions in tracheal segments in the group of dead newborn due to MAS and the group of newborn that have died due to distress respiratory syndrome (DRS) in human material.

Relying in the results of our research and of other authors, we can conclude that the effect of the amniotic fluid in the vascular and airways smooth musculature in newborn is an important effect and it has impact on reaction of these tissues.

Difference in the contractile response of the smooth musculature of the pulmonary artery and the tracheal segments and controlling groups is considered that it may be as a result of differences of the action of mineral substances in the composition of amniotic fluid and eventual differences in the neuronal structure of the respiratory vascular vessels and airways.

\section{Conclusion}

Based on gained results, it can be ascertained as follows:

1. In vitro, acetylcholine does not cause significant reaction of the pulmonary artery in cases of aspiration of the amnional fluid $(\mathrm{p}>0.1)$.

2. Histamine in vitro in cases of death from the aspiration of the amnional fluid cause significant contraction of the pulmonary $\operatorname{artery}(\mathrm{p}<0.01)$.

3. Tracheas in newborn, as a controlling group, which has died from the MAS and DRS syndromes, acetylcholine 
and histamine, have caused significant response at in vitro conditions $(\mathrm{p}<0.01)$.

4. In the syndrome of the aspiration of the amnional fluid exists a high content of the magnesium in meconium, which plays an important role and obstructs the entry of calcium in cells by causing relaxant effect. Superoxide also increases the relaxation of musculature by entering into reaction with oxygen and by reducing bioavailability of the nitric oxide. Role of the oxygen in changing of the reaction of the smooth musculature of pulmonary artery is closely related with the syndrome of aspiration of the meconial fluid.

\section{References}

1. Tølløfsrud PA, Medbø S, Solås AB, Robertson B, Speer CP, et al. (2004) Intratracheal albumin reduces interleukin-8 in tracheobronchial aspirates in piglets after meconium aspiration. J Perinat Med 32: 78-83.

2. Cleary GM, Wiswell TE (1998) Meconium-stained amniotic fluid and the meconium aspiration syndrome: an update. Pediatr Clin North Am 45: 511-529.

3. Dargaville PA, Copnell B (2006) The epidemiology of meconium aspiration syndrome: incidence, risk factors, therapies, and outcome. Pediatrics 117 1712-1721.

4. Righetti C, Peroni DG, Pietrobelli A, Zancanaro C (2003) Proton nuclear magnetic resonance analysis of meconium composition in newborns. J Pediatr Gastroenterol Nutr 36: 498-501.

5. Rodrigues CM, Marin JJ, Brites D (1999) Bile acid patterns in meconium are influenced by cholestasis of pregnancy and not altered by ursodexycholic acid treatment. Gut 45: 446-452.

6. Haram-Mourabet S, Harper RG, Wapnir RA (1998) Mineral composition of meconium: effect of prematurity. J Am Coll Nutr 17: 356-360.

7. Holopainen R, Aho H, Laine J, Peuravuori H, Soukka H, et al. (1999) Human meconium has high phospholipase A2 activity and induces cellular injury and apoptosis in piglet. J Perinatology 46: 626-632.

8. Zagariya AM, Bhat R, Zhabotynsky E, Chari G, Navale S, et al. (2005) Characterization of serine/cysteine protease inhibitor alpha1- antitripsin from lungs. J Cell Biochem 96: 137-144.

9. de Beaufort AJ, Bakker AC, van Tol MJ, Poorthuis BJ, Schrama AJ, et al. (2003) Meconium is a source of pro-inflamatory substances and can induce cytokine production in cultured A549 epithelial cell. Pediatr Res 54: 491-495.

10. Holopainen R, Aho H, Laine J, Peuravuori H, Soukka H, et al. (1999) Human meconium has high phospholipase A2 activity and induces cellular injury and apoptosis in piglet lungs. Pediatr Res 46: 626-632.

11. Berdelli A, Akisu M, Dagci T, Akisu C, Yalaz M, et al. (2004) Meconium enhances platelet-activating factor and tumor necrosis factor production by rat alveolar macrophages. Prostaglandins Leukot Essent Fatty Acids 71: 227-232.

12. Kytola J, Kaapa P, Uotila P (2003) Meconium aspiration stimulates cyclooxygenase-2 and nitric oxide synthase-2 expression in rat lung. Pediatr Resp 53: 731-736.

13. Khan AM, Lally KP, Elidemir O, Colasurdo GN (2002) Meconium enhances the release of nitric oxide in human airway epithelial cell. Biol Neonate 81: 99-104.

14. Tyler DC, Murphy J, Cheney FW (1978) Mechanical and chemical damage to lung tissue caused by meconium aspiration. Pediatrics 62: 454-459.

15. Tran N, Lowe C, Sivieri EM, Shaffer TH (1980) Sequential effects of acute meconium obstruction on pulmonary function. Pediatr Res 14: 34-38.

16. Oelberg DG, Downey SA, Flynn MM (1990) Bile salt-induced intracellular Ca++ accumulation in type II pneumocytes. Lung 168: 297-308.

17. Katz VL, Bowes WA (1992) Meconium aspiration syndrome: reflections on a murky subject. Am J Obstet Gynecol 166: 171-183.

18. Mokry J, Mokra D, Nosalova G (2006) Direct in vitro effects of meconium on airway reactivity in adult rabbits. Bratisl Lek Listy 107: 9-11.
19. Tølløfsrud PA, Medbø S, Solas AB, Drevon CA, Saugstad OD (2002) Albumin mixed with meconium attenuates pulmonary dysfunction in a newborn piglet model with meconium aspiration. Pediatr Res 52: 545-53.

20. Montgomery LD, Belfort MA, Saade GR, Moise KJ, Vedernikov YP (1995) Meconium inhibits the contraction of umbilical vessels induced by the thromboxane A2 analog U46619. Am J Obstet Gynecol 173: 1075-1078.

21. Altshuler G, Hyde S (1989) Meconium-induced vasocontraction: a potential cause of cerebral and other fetal hypoperfusion and of poor pregnancy outcome. J Child Neurol 4: 137-142.

22. Righetti C, Peroni DG, Pietrobelli A, Zancanaro C (2003) Proton nuclear magnetic resonance analysis of meconium composition in newborns. J Pediatr Gastroenterol Nutr 36: 498-501.

23. Holopainen $\mathrm{R}$, Aho $\mathrm{H}$, Laine J, Peuravuori H, Soukka H, et al. (1999) Human meconium has high phospholipase A2 activity and induces cellular injury and apoptosis in piglet lungs. Pediatr Res 46: 626-632.

24. Zagariya AM, Bhat R, Zhabotynsky E, Chari G, Navale S, et al. (2005) Characterization of serine/cysteine protease inhibitor alpha1-antitripsin from meconium-instilled rabbit lungs. J Cell Biochem 96: 137-144.

25. Haram-Mourabet S, Harper RG, Wapnir RA (1998) Mineral composition of meconium: effect of prematurity. J Am Coll Nutr 17: 356-360.

26. Gourgoulianis KI, Chatziparasiddis G, Chatziefthimiou A, Molyvdas PA (2001) Magnesium as a relaxing factor of airway smooth muscles. J Aerosol Med 14 301-307.

27. Soukka HR, Ahotupa M, Ruutu M, Kaapa PO (2002) Meconium stimulates neutrophil oxidative burst. Am J Perinatol 19: 279-284.

28. Hawang SJ, Lee KH, Hwang JH, Choi CW, Shim JW, et al. (2004) Factors affecting the response to inhaled nitric oxide therapy in persistent pulmonary hypertens. Yonsei Med J 45: 49-55.

29. Aaltonen M, Soukka H, Halkola L, Jalonen J, Holopainen IE, et al. (2005) Meconium aspiration induces oxidative injury in the hippocampus of newborn pigles. Early Hum Dev 81: 439-47.

30. Craing S, Lopez A, Hoskin D, Markham F (2005) Meconium inhibits phagocytosis and stimulates respiratory burst in alveolar macrophages. Pediatr Res 57: 813-818.

31. Zoer B, Kessels L, Vereijken A, De Mey JG, Bruggeman, V, et al. (2009) Effects of prenatal hypoxia on pulmonary vascular reactivity in chickens prone to pulmonary hypertension. J Physiol Pharmacol 60: 119-130.

32. Tessler R, Pan J, Fiori HH, Belik J (2008) Human Meconium Has a Pulmonary Vascular and Airway Smooth Muscle Relaxant Effect. Pediatr Res 64: 24-28.

33. Collins LC, Roberts AM, Robinson TW, Joshua IG (1996) Direct effects of meconium on rat tracheal smooth muscle tension in vitro. Pediatr Res 40: 587-591. 